\title{
Can Community Resettlement be Considered a Resilient Move? Insights from a slow-onset disaster in the Colombian Andes
}

The degree to which communities can best withstand various forms of external stress, as well as what constitutes community resilience has been a matter of debate in discussions of development, resilience building, adaptation and transformation. Drawing on insights from a field expedition to the indigenous reserve of Aponte in the Colombian Andes, this paper engages with the concept of transformationaland community resilience and problematizes the concept focusing particularly on its tendency to assume that disasters are one-off, sudden events that allow for sustainable recovery in their aftermath. Aponte faces complete ruination by a slowonset geological hazard which has prompted discussions of relocation among other solutions - raising questions of whether and how resilience can be understood in the context of perpetually worsening conditions of environmental change.

Keywords: slow-onset disaster, Colombia, Andes, State distrust, resettlement, disaster risk reduction (DRR)

\section{Introduction}

Research on community resilience against disasters as well as on disaster-induced displacement and relocation has surged in recent decades (Cernea and Maldonado, 2018; Patel et al. 2017; Oliver-Smith, 2009). Disaster-stricken communities have been shown to exhibit remarkable organizational capabilities in the aftermath of destruction, temporarily setting aside internal conflicts which may have been prevalent prior to the event (Aldrich, 2012; Tierney and Oliver-Smith, 2012). Similarly, research on relocation suggests that disaster-stricken communities actively resist such efforts; indeed - some of those affected return to the rubble from whence they came, determined to make life work there again (Oliver-Smith, 1991; Oliver-Smith, 1977). With only few exceptions, however, research on community resilience as well as research on displacement and relocation has been dominated by case studies of rapid-onset disasters, such as earthquakes, landslides, avalanches and floods (Matthewman, 2015). But what do we 
know about community resilience and displacement patterns in the context of incremental and slow-onset disasters?

Disaster scholarship has long been accused of ignoring creeping disasters in their theoretical contributions, which has been partially offset by development scholars working on droughts and famines (Matthewman, 2015). Indeed, disaster scholarship as such remains dominated by theories and frameworks borne out of research on suddenonset disasters (Staupe-Delgado, 2019; Hsu, 2017; Dynes, 2004). Earlier debates on the phenomenon and concept of disaster often argued for limiting the analytical focus to sudden and unexpected events (cf. Stallings, 2005; Quarantelli, 1998), seeing gradual processes as outside of the scope of disaster research. The dynamics of community resilience as well as the effects disasters have for this reason not been sufficiently explored in the existing literature on disasters and development.

In this article I problematize the concept of community resilience against disasters in light of a field expedition to the indigenous reserve of Aponte in the Colombian Andes. Aponte is currently experiencing a slow-onset geological disaster which has prompted discussions of relocation, among other solutions. The political process is further challenged by community distrust towards the local authorities. The Aponte disaster in many ways sheds new light on the on-going scholarly debates in the development field concerning post-disaster relocation and community resilience in terms of not only indigenous politics, state distrust and social cohesion but also due to the multi-faceted nature of the community-resilience concept.

This article engages with these literatures and raises some important questions emerging from the Aponte disaster, and is structured as follows: the subsequent section elaborates on the two key concepts this paper engages with, namely community resilience and post-disaster resettlement; the third section elaborates on the field context, including 
the community of Aponte and the creeping disaster affecting it, and the debates regarding relocation as a recovery option; the fourth section problematizes the concept of community resilience, followed by a fifth and concluding section which summarizes the discussions presented in the paper.

\section{Theoretical framework: community resilience and post-disaster resettlement}

Minimising the global burden of disasters hinges on adopting a more proactive approach to disaster risk, which in turn can be considered a precondition for sustainable development (UN, 2015). Governments vary in the degree to which they invest in risk reduction measures prior to actual disaster events. Difference in economic ability, prevailing political climate and culture are only some of the factors which shape how authorities and communities approach and implement hazard adjustments (McEntire and Myers, 2004; Lindell, 1997). Vulnerability theories of disaster (cf. Adger, 2006; Wisner et al. 2004; Cutter, 1996) therefore see disasters as a product of society itself rather than of natural processes. How societies deal with disaster risk, in turn, depends on a broad range of factors and actions occurring both before and after impact.

The literature on community resilience builds on previous scholarship centred on vulnerability (for more in this development see for example: Birkmann, 2013; Gaillard, 2010), and has become a key concept in development studies (Béné et al. 2017; Gaillard, 2010). The concept remains elusive and difficult to define, especially in local and operational contexts (Norris et al. 2008; Manyena, 2006). However, a generous reading of this literature identifies a core set of traits or themes generally associated with resilient communities that may be used as a baseline for discussing this highly contested concept.

Resilience is typically understood as relating to either community ties or infrastructure and the built environment. Perhaps best understood as a separate literature 
on 'resilience engineering', the infrastructural aspect of resilience focuses on the ability of the material space to withstand the physical shocks triggered by the hazardous event (Hassler and Kohler, 2014; White and O'Hare, 2014; Bosher and Dainty, 2011). Other work has focused more on community cohesion, trust and social attributes of resilience, referring more explicitly to the resilience of communities rather than the resilience of the built environment (Cutter, Boruff and Shirley, 2006; Wisner et al. 2004). A focus on social capital, social cohesion and societal trust is in many ways at the core of community resilience scholarship. Daniel Aldrich, for instance, critiques infrastructural and engineered solutions and argues for increased attention to trust and community-building initiatives (Aldrich and Meyer, 2015; Aldrich, 2012). Recognizing that community capacities can be drawn on across disaster-related activities (ranging from mitigation to recovery), community resilience conceptualizations focusing on the social are a reaction to expert-centred, top-down approaches to disaster management. Community resilience can in this sense more productively framed as 'emergent and relational' (Barrios, 2014: 329). Also, communities do not exist independently from society at large. Far less is known about communities characterized by high degrees of social cohesion but where society at large is not. It would therefore be fallacious to assume that communities are resilient by definition. As pointed out by Tobin (1999: 13), there are good reasons to be sceptical of the way in which the term has been employed as the 'holy grail' of disaster research. Research on equity and marginalization, for example, suggests that community can be a difficult term where social expectations are centred on difference and assimilation (Martin, Forrester and Ensor, 2018; Chandrasekhar, 2012), indicating that the concept of community may in some cases paint an overly rosy picture which writes struggles and community oppression out of the narrative. Pre-disaster conditions of vulnerability therefore clearly shape post-disaster outcomes. Even though phases like 
'pre-disaster' and 'post-disaster' can be difficult to employ in the context of slow-onset, gradually manifesting disasters - there will still be, in a sense, a point after which a place has been rendered destroyed or otherwise ruined. In this case, thinking about community relocation following disaster, it remains unclear how community resilience and postdisaster relocation are connected and whether these notions are even compatible.

The literature on environmental change stresses the relationship between socioeconomic vulnerabilities, resilience and the ability of social systems, including communities, to adapt to change, stress and other perturbations (Pelling, O'Brien and Matyas, 2015). This perspective holds that communities cannot be understood in separation from the environment in which they are located. At the same time, the hazardousness of these environments are seen as a product of this relationship. This implies that, broadly speaking, low-grade processes of environmental change or even sudden events may either cause communities to: collapse, in the sense that the community as such is destroyed, dispersed, displaced or otherwise ceases to be the same community - qualitatively speaking; adapt, meaning that a community incrementally alters its organisation so as to keep up with the gradual change process; or deliberately transform in a radical way so that the underlying conditions no longer pose a major threat (Schlosberg, Collins and Niemeyer, 2017; Gibson et al. 2016; Glantz 1994). More specifically, transformational resilience is characterised by

Radical shifts, directional turns or step changes in normative and technical aspects of culture, development or risk management. Both adapting systems and surrounding environments can be subject to transformation, with non-linear change being either intentional or unexpected (Pelling, O'Brien and Matyas, 2015, p. 133). 
As can be gleaned from this description transformation as a concept is chiefly concerned with leapfrogging past incremental adaptation by instead striving to increase community robustness in a focused and determined way so as to avoid falling short on adaptation targets and risk community collapse. In the specific case of the creeping disaster in Aponte, however, disaster risk is expected to increase exponentially as the disaster unfolds. The question remains, therefore, can community resettlement be considered a resilient (or transformational) move-or is it indicative of community collapse? One can reasonably expect the answer to me multifaceted, but include among other factors the quality and inclusiveness of the resettlement process and whether we consider what I call 'recovering elsewhere' (as opposed to in-situ, due to the original site having been rendered an uninhabitable ruin) as indicative of transformative resilience.

There is broad agreement that resettlement following a disaster is associated with many adverse consequences, and should therefore be considered an intervention of last resort (Cernea and Maldonado, 2018; Oliver-Smith, 1991). Although studies of development-induced displacement suggests that comprehensive resettlement planning has been shown to make a difference on resettlement outcomes (Oliver-Smith and de Sherbinin, 2014), the agency of individual community members cannot be ignored. It is not uncommon for resettlement projects to fail due to lack of community participation, which in turn means that many households are often left without livelihood opportunities (Cernea, 1997). It is also commonly observed that the alternative site is either partially or fully rejected for these reasons (Oliver-Smith, 1991; 1977), or as a result of inappropriate housing facilities and other failures of integrating cultural aspects of resettlement, which arguably constitutes a case of community collapse as the community dynamics and demographic makeup will be radically changed as a result. 
What constitutes sustainable or adequate recovery following a disaster event is a matter of debate. The degree to which a community has recovered ultimately depends on the factors considered (Tierney and Oliver-Smith 2012). Recovery has often been conflated with the concept of reconstruction, thereby reducing recovery to material considerations. However, most definitions of disaster recovery emphasise the socioeconomic dimension of the term, such as that used by the United Nations Office for Disaster Risk Reduction (UNISDR, 2017):

The restoring or improving of livelihoods and health, as well as economic, physical, social, cultural and environmental assets, systems and activities, of a disaster-affected community or society, aligning with the principles of sustainable development and "build back better", to avoid or reduce future disaster risk

Disasters can linger on for years after a natural hazard has dissipated and can negate decades of local-level development gains in the absence of timely and broad-based recovery (Sawada and Takasaki, 2017). Chronic injuries following a disaster can render many survivors unable to work and dependent on family members (see for example Pelham, Clay and Braunholz, 2011; Fjord and Manderson, 2009). Farmers who lose their crops due to floods or droughts may become indebted, rendering them less resilient to future adverse events (Udmale et al. 2015). Further, the livelihoods of local producers may be at risk of market failure as a result of international aid, which is partially why cash-transfers are now often preferred (Régnier et al, 2008; Harvey, 2007). As all of these examples point out, recovery is often fragile and for many the disaster will not be over just because the hazardous event or process is. In cases where the hazardous event does not dissipate, but instead increases in intensity and severity over time, it may be necessary to resettle the community at an alternative site. In such situations, it is vital that measures 
are taken to minimize the adverse consequences of resettlement. After all, even if just a small number of households reject the new settlement and settle elsewhere, such seemingly small failures risk jeopardizing the recovery process altogether as the community may have been changed too drastically to resemble the previous community in any meaningful way.

\section{The creeping disaster in Aponte}

This study draws on data collected during a field expedition to Aponte as well as secondary data gathered from news reports and official documents to shed light on the slow-onset geological disaster in Aponte, both part of a three year fieldwork project focussed on studying preparedness for slow-onset disasters in the Colombian Andes. A research expedition to Aponte in May 2016 serves as the main empirical basis of the present article ${ }^{\mathrm{i}}$. The material used in this article stems from interviews with local experts at the Gobernación de Nariño in Pasto, municipal leaders in Aponte, UNDP officials in Pasto, as well as members of affected households affected by the creeping disaster in Aponte (see Figure 1). This primary data, in turn, has been supplemented with secondary data from Colombian news and special coverage of the situation in Aponte. Prior to the signing of the Colombian Peace Agreement at the end of 2016, Nariño and Putumayo were considered among the most at-risk areas in the country (UK Foreign and Commonwealth Office, 2016), and great care therefore had to be taken when traveling around Nariño.

\section{(a) Aponte}

Aponte is located approx. 30 kilometres north east of the sub-national capital of Pasto (see Figure 1), which until recently was part of the zona roja - or the no-go zone in the department (sub-national jurisdiction) of Nariño. Colombia has experienced one of 
the longest guerrilla wars in history, which formally ended in late 2016 upon the ratification of the peace agreement between the Government of Colombia and the Fuerzas Armadas Revolucionarias de Colombia (FARC).

\section{[Figure 1 about here]}

The peace, however, remains contested and in a fragile state (Chagas-Bastos, 2018; Retteberg, 2018). In the midst of the Colombian conflict, the indigenous peoples of Aponte, the Inga, resisted guerrilla occupation of their lands and successfully reclaimed their ancestral territory. With a population of just under 4000 and a reserve spanning well over 22,000 hectares, the Inga of Aponte were awarded the UNDP-backed Equator Prize in 2015 for their peaceful resistance:

Following expulsion of these groups, the Inga people set aside the majority of their land as a 17,500 hectare sacred area. The community organized themselves around a local governance model that is based on shared a vision of justice and collective action on health, education, community services, ecosystem restoration, and sustainable livelihoods. At the same time, the group created the Court of Indigenous Peoples and Authorities from the Colombian Southwest, designed to support other indigenous peoples in reclaiming their ancestral territories and combatting drug trafficking (Equator Initiative, 2015).

The Inga of Aponte are in many ways a well-governed community characterized by high social cohesion and facilitative of active participation in communal decision-making processes (Chindoy and Chindoy, 2017). The town council, which operates under indigenous law, is made up of town ministers, about half of which are women. Collective decision making is to a large extent practiced, and the council meets regularly to discuss 
issues of collective concern. Past achievements, such as those that secured them the Equator Prize, have in the past proved highly effective and can be considered indicative of an unusual political skill on a level far higher than most Nariñense pueblos of similar size. Aponte is also home to one of the best elementary schools in the municipality of El Tablon de Gomez, and the Inga are also producers of the now world-famous Nariño coffee. Given the above, one would be correct to conclude that Aponte is in many ways a highly resilient community, at least if its wider societal context is not considered. However, Aponte is currently facing a creeping disaster (a disaster still unfolding and intensifying exponentially) of such a magnitude that talk of resilience or transformation hardly seems appropriate without considering these terms in relation to community resettlement.

\section{(b) The natural phenomenon affecting Aponte}

Aponte is currently experiencing what appears to be slow-onset geological disaster causing ever-widening cracks to appear all around the peaceful town (most likely a multiple retrogressive slumping mass movement, but the geological nature of the natural hazard is not relevant for the discussions that will follow). In the words of the community, the phenomenon is described in terms of the town sinking into the ground, being eaten away at by the soil, or the town being swallowed by the earth. Stretching in all directions, these mysterious earth cracks are everywhere, causing buildings to collapse, and are not likely to stop growing over time.

Nearly three years have passed since the first cracks started appearing around and in homes around the Indigenous reserve of Aponte. Members of the Inga report having initially witnessed cracks appear in the soil and grass, which have subsequently expanded and multiplied at an exponential rate over time $\mathrm{i}^{\mathrm{ii}}$. One fault in particular has received 
attention, and have in many ways become the reference point for following the onset of the phenomenon (see Image 1).

\section{[Image about here]}

The fault in the image was initially only a crack in the ground similar to the one to the left of the image. It soon became clear, however, that the town is at risk as faults all over town started growing in size and height-proportion. The cracks initially manifested as cracks in lawns, small slopes in roads as well as small, relatively undramatic cracks around the doors and windows of people's homes. The first few months were therefore relatively uneventful, as can be considered typical for gradually manifesting disaster types. It should be noted that field conversations, news articles and official reports on the Aponte disaster can by no means adequately capture the sentiments of the Inga. Local experiences and perceptions of the event are multi-layered, continuously (re)negotiated and diverse. The following account, while attempting to provide as detailed as possible an overview of the situation and its social effects, is therefore in no way exhaustive.

\section{i) Initial signs of calamity}

Many affected families and individuals reported that the initial impacts were not considered alarming or indicative of what would follow. 'It began with a thin, threadlike crack, then another - and soon the entire floor was split in two (se partió)'. It is relatively clear from this excerpt that the cracks were not initially seen as part of a larger process or phenomenon. A number of affected families expressed that they had felt surprised when they after some time realized that their homes continued to sustain damage over time. Yet, one woman describes having felt that something was amiss as she had 'witnessed 
cracks appearing at a faster rate'. These people who first started experiencing the phenomenon had experienced great uncertainty until it became clear that these were not isolated occurrences and that the cracks continued to widen and multiply.

The speed at which the phenomenon progressed was also a source of concern and uncertainty among affected families. A man pointing to cracks going from floor to ceiling - with smaller cracks also going across the floor - describes how it 'developed slowly but now one sees how it has advanced already'. The cracks vary in size and shape, some houses appeared more as if broken in two - like a clean cut - while others seemed to be crumbling, with cracks coming from many different directions. In the words of a town representative, the 'first cracks were about hairline-thick, and two weeks later like a pencil'. Later victims experiencing the same manifestations knew what to expect, as expressed by a neighbour stating that 'is already causing us fear because of the tragedies from the beginning'. The first unsuspecting victims therefore did not know what to expect, perhaps thinking or hoping that every new crack would be the last - and that these could be repaired with relative ease. As the natural hazard progressed, then, ever increasing number of families whose houses were also breaking or crumbling knew what to expect, as the homes of the initial victims had already collapsed or been abandoned.

\section{ii) Local interpretations, patterns and observations}

Views on the nature and significance of the phenomenon were diverse and plentiful. While most community members did not have much to say on the origins of the phenomenon or its pattern of manifestation, those who did had noticed a connection between progression of onset and weather conditions. One woman stated that 'it's when it's windy that it moves'. Others have observed that tremors and cracks are more frequent on sunny days. Many also experience more geological activity at night. Even though the 
exact nature of causation or pattern of manifestation is difficult to arrive at - it is plausible that the search for reliable patterns is attributable to the deep uncertainty faced by the community.

For some community members the calamity was seen as a warning. A village representative is convinced that the process is a sign, as can be read from an interview with a local news channel:

Nature is not trying to break us; it's providing us with a wake-up call as to what we are doing to it. We have perhaps exploited the generosity of Mother Earth by imposing outside ways like excessive deforestation ${ }^{\text {iii }}$.

To the village representative the slow-onset disaster in Aponte is akin to a symptom of illness. Deforestation is identified among a range of foreign practises that could be a potential cause of the malady. As became clear in a different conversation, this is a central aspect of the cosmovisión of the Inga and of indigenous peoples of the Andes in general (see for example Gordon, 2014; Dover, 1995). Local interpretations of the relief effort can in this way be understood as operating along two pathways - one focused on easing the suffering of the affected population and one centred on remedying the connection between community and the environment.

\section{(c) Response}

Resettlement was presented as the only viable response already at an early stage of the unfolding disaster. While engineered solutions to these and similar phenomena have been successfully implemented elsewhere (e.g. in the Italian town of Montelupone), such measures are likely to be too costly of an option for a community like Aponte or the departmental government of Nariño. The planned resettlement process as it was presented 
to us in 2016 consists of a number of stages: 1) the provision of temporary shelter for families who lost their homes or whose homes are too dangerous to occupy; 2) a survey aimed at identifying the nature of the phenomenon affecting Aponte; 3) a comprehensive risk assessment of nearby sites that may potentially serve as the site for New Aponte; 4) and lastly the construction of New Aponte. In what follows an important caveat must be made. The field data are mainly from mid-2016 at which time the disaster was relatively advanced (as per the photos), but the response plan was only in its infancy. In order to provide insight on more recent stages of the process, therefore, the field observations have been supplemented by more recent data from documents, news reports and newspapers. Before discussing the way forward in the next sub-section, it is necessary to paint a more detailed picture of the unmet needs of the Inga throughout the disaster onset period, and the measures aimed at addressing them.

\section{i) Unmet community needs}

Those whose homes have collapsed and those who feel that their homes mostly chose to live with relatives or rent a house elsewhere in the region. A smaller number had been moved to a temporary relief shelter. However, displaced populations living in temporary shelter as a result of having lost their homes to the disaster have not found the shelters adequate. The shelters do not have running water or proper hygienic facilities, meaning that many families only occupied the shelters for short periods of time in between stays with friends and relatives:

Shelters have been set up but we can't live in them. They don't have water or sewage, so we can't live there - only stay - we come at night to sleep but no more. Living permanently is impossible. We can't without services. We have to rent elsewhere or live in the damaged houses risking our lives 
People of poor health, the elderly and disabled residents have found the process particularly challenging (as is commonly the case, see for example Kelman and Stough, 2015 for an overview). Unable to live in shelters that lack basic services, those who are ill, particularly those who do not have family elsewhere, find themselves forced to occupy at-risk homes:

For me this is very hard, thinking that this [house] could fall to the ground. [..] Hearing that I have to leave is very hard; it is very painful because I don't have anywhere to go to - and I'm ill. Yesterday I came from the hospital and also my spouse is suffering from a back injury.

Living in uncertainty with only periodic updates on the process and its potential outcomes has been a source of great uncertainty. Frustrated with the sluggish response, one community member comments that 'many people have come, but they have simply come to check [carry out studies?] and then nothing happens.' Others would like 'that they [the authorities] collaborate' and that 'they do their utmost.' Still, the biggest cause of anxiety seems to be the combined effect of not having been informed about the onset of the phenomenon or how the resettlement progress will be implemented:

The uncertainty is big because I don't know what will happen. It's possible that the house could collapse or simply this start to crumble. [... I still live in this house with my children and my husband, and we don't have any answers.

For affected community members to describe their uncertainty in this way (lack of options, no answers) points to the importance of communication in decreasing uncertainty 
and providing some level of predictability. In a sense, it appears as though poor communication regarding the relief process is at least as big a concern as the disaster process itself.

\section{(d) Anxieties and concerns among the Inga}

Thinking about resettlement and the possibility that the community could collapse is a source of significant anxiety among the Inga. There appear to be few alternatives to resettlement on the table, and even though both the authorities and community leaders have recognized it as an undesirable solution, there still seems to be broad agreement that it is necessary as a solution of last resort. While all the narratives collected here express concern and reluctance to relocate, there is also a clear tendency for some community members to accept and indeed desire resettlement (most likely as a means of moving on, starting anew), and those who are reluctant, wanting to stay behind in the ruins of Aponte. The former set of narratives will here be juxtaposed with the latter, before we move on to discuss the implications of the Aponte disaster for discussions on community resilience prevailing in the academic literature.

Community resettlement has been identified as a major source of anxiety, trauma and stress both at the planning stage and at the post-resettlement stage (Cernea and Maldonado, 2018). Even though many, perhaps the majority of the Inga have come to terms with relocation as an option of last resort, the study informants report that their biggest fear is to be dispersed - for the community to collapse or be radically changed. 'Because several houses that we have here have collapsed, the fear is that we have to separate some to one side and others to another side'. A young man stressed that communal living is central to the Inga - 'our people have always lived together as a community therefore we can't risk being scattered here and there (para allá y para acá)'. It is in other words about the survival of the community. Another informant sees it as a 
duty towards God - 'as indigenous people we can't be dispersed, we want to continue to live collectively and obey God'. What is a community - and how much can a community change before it becomes a different community altogether? In Aponte as in most cases around the world, the decision of resettlement is resisted by several members of the community, including an Inga representative who in a TV interview stated that:

Despite having lost all of our assets, we are not going to leave this place; we were born here and this is also where we will die. Some of our brothers left the territory for cities like Cali, Pasto or Bogota - or went to Ecuador. When our town recovers again, many of them will return. If not they themselves, their children or grandchildren will return. Those of us who remain here have the responsibility to continue taking care of our territory, to continue living in this space throughout time.

Implicit in this statement is a sentiment that leaving represents a form of betrayal, even though it is not sanctioned. Remaining is considered a duty because, as one lady noted 'to me, an Inga town as an Indigenous Reserve is not worth anything without territory, the territory is the primary subsidence for people [here]'. There are many reasons for why resettlement is an unattractive option for the Inga, one of them being the role their spaceboundedness and their connection to their territory plays in the cosmovisión Inga:

History tells us that our founder and chieftain Carlos Tamavio left us in this territory from the 1600s-1700s. From the perspective of the cosmovision Inga we believe that he comes to visit us in the main square each year. 
Concerned that the departmental government in Nariño will not take the cosmovisión and the rights of indigenous people into account, a town council meeting attended during an expedition to Aponte made it clear that Inga leaders are distrustful towards Colombian authorities. International organizations or foreign donors, it was noted, had a better history of trying to include indigenous concerns in programming, and the involvement of UNDP Colombia was desired. In later conversations with participants at the meeting, it also became clear that a strategic focus for the Inga was to 'ask the national and international authorities to maintain their presence so that a solution can be found'. However, because the risk management and disaster unit in Nariño sits with the formal responsibility such involvement would be difficult and challenge the principle of proximity, which stipulates that disaster response initiatives should be managed at the lowest possible level of governance. The involvement of international and foreign actors, therefore, even though requested by the Inga, would challenge the authority of the Nariñense government and probably be in violation of the mandates of international organizations and donor countries.

\section{Concluding reflections}

The Inga of Aponte possess many of the traits typically associated with resilient communities. Their successful resistance against guerrilla and paramilitary groups throughout the Colombian conflict, as well as their eradication of illicit crops in favour of coffee cultivation are but some examples of strong leadership on part of the Inga. These hard-won gains were also cited as reasons for awarding the Inga with the Equator Prize in 2015, and is in turn indicative of their strong position in Colombian indigenous politics and activism. In other words, the Inga, although a minority in the region of Nariño, defies typical conceptions of vulnerable or marginalized populations in the way they have worked to shape their own destiny and preserve their autonomy over centuries. It is also 
unclear whether a community can be considered resilient if it happens to be located in an insecure society. For these reasons, the community of Aponte challenges prevailing understandings of community resilience which are largely focused on internal community characteristics. But what about external factors - is it possible to be resilient against perpetual natural hazard impacts that will not cease, but instead continue to intensify over time?

The literature on resilience and disasters teaches us that communities under stress may either adapt, transform or collapse in the face of adversity (Pelling, O'Brien and Matyas, 2015; Folke et al. 2002). Drawing on studies of sudden-onset disasters models of vulnerability and resilience demonstrates how disasters reoccur or cascade, putting communities at risk of entrapment in a negative spiral of vulnerability until coping capacities are eventually exhausted. This dynamic, however, has not been explored sufficiently for slow-onset disasters. Insights and reflections from the Aponte disaster raises the question of how resilience dynamics might work under conditions of constant and escalating stress - stress that eventually will require communities to relocateraising the question of whether resettlement can be considered a resilient move and under what conditions?

Scholarly debates on resettlement now universally recognize resettlement as an option of last resort due to its immense social consequences. In thinking about the concept of community resilience an important yet underexplored question is whether community relocation constitutes collapse. In the process of displacement and eventual relocation a number of community members inevitably choose to relocate elsewhere, such as to larger cities where they may have relatives, or remain at the old site, which previous ethnographic studies have demonstrated (e.g. Oliver-Smith, 1977). In Aponte, for example, prominent community leaders have expressed that they feel obliged to remain 
and safeguard the old site. As we have seen from the above excerpts, other members of the Inga have already been displaced throughout Colombia and now reside in cities like Cali or Bogotá.

So, can community resettlement be considered a resilient move? The answer to this question is not straightforward. Even though the literature has identified community resettlement as an option of last resort as well as practices that minimizes adverse consequences, it also vividly portrays the disastrous impacts suffered by communities that have been relocated in the past. Climatic change is projected to increase the need for community resettlement due to slow-onset processes such as sea-level rise or erosion, and further ethnographic explorations of this question will therefore be needed. In general terms, however, it appears as though adaptation or transformation in-situ are not viable options in the context of perpetual slow-onset disasters that will not dissipate. Community resilience, as it is typically defined, may therefore seem as a relatively awkward concept in such cases as resisting such phenomena does not seem possible or at least feasible. In other words, while the literature on resilience generally assumes that communities can withstand or bounce back from disasters, some disasters (such as the one affecting Aponte) may leave little scope for responses other than resettlement.

One could argue that if the process of displacement and resettlement results in the existence of a new town where resettled members of the Inga reside - and an old town inhabited by those who either refuse to resettle (or people who eventually return to rebuild their old homes), this would in some ways constitute a resilient outcome. Similarly, if Aponte is completely abandoned with time and a similar community dynamic can be created at the new site, this could also be considered a resilient outcome. What remains less clear is how different or changed the resettled community can be while still remaining the same community - and whether too big changes constitute adaptation, transformation 
or collapse. Many of these questions demonstrate both the limited contexts to which the concept of community resilience has been applied as well as the tendency to see resettlement as antithetical to transformational resilience, both of which imply a need to conduct more studies of creeping disasters and gradual processes of environmental change that will not dissipate, but rather intensify over time, rendering adaptation or transformation in-situ unfeasible options.

\section{Acknowledgements}

Acknowledgements: I wish to thank the UNDP for organizing the field expedition to Aponte in 2016. I also wish to thank David Alexander for his useful reflections on the nature of the geological phenomenon. Further, I would like to thank Oscar A. Staupe-Delgado and Gelvin W. Herrera for their help at various stages of the process.

\section{References}

Adger, W. N. (2006). Vulnerability. Global Environmental Change, 16(3), 268-281.

Aldrich, D. P. (2012). Building resilience: Social capital in post-disaster recovery. Chicago: University of Chicago Press.

Aldrich, D. P., \& Meyer, M. A. (2015). Social capital and community resilience. American Behavioral Scientist, 59(2), 254-269.

Barrios, R. E. (2014). 'Here, I'm not at ease': anthropological perspectives on community resilience. Disasters, 38(2), 329-350.

Béné, C., Chowdhury, F. S., Rashid, M., Dhali, S. A., Johan, F. (2017). Squaring the circle: Reconciling the need for rigor with reality on the ground in resilience impact assessment. World Development, 97(2017), 212-231.

Birkmann, J. (2013). Measuring vulnerability to promote disaster-resilient societies: Conceptual frameworks and definitions. In J. Birkmann (Ed.), Measuring vulnerability to natural hazards: Towards disaster resilient societies (pp. 9-54). Tokyo: United Nations University Press.

Bosher, L., \& Dainty, A. (2011). Disaster risk reduction and 'built-in' resilience: Towards overarching principles for construction practice. Disasters, 35(1), 1-18.

Cernea, M. (1997). The risks and reconstruction model for resettling displaced populations. World Development, 25(10), 1569-1587. 
Cernea, M. M., \& Maldonado, J. K. (2018). Challenging the prevailing paradigm of displacement and resettlement: Its evolution, and constructive ways of improving it. In M. M. Cernea, \& J. K. Maldondo (Eds.), Challenging the prevailing paradigm of displacement and resettlement: Risks, impoverishment, legacies, solutions (pp. 1-42). Abingdon: Routledge.

Chagas-Bastos, F. H. (2018). Colombia's Peace in tatters. Journal of Peacebuilding \& Development, 13(2), 127-134.

Chandrasekhar, D. (2012). Digging deeper: participation and non-participation in postdisaster community recovery. Community Development, 43(5), 614-629.

Chindoy, H. C., \& Chindoy, L. A. (2017). Wuasikamas - El modelo del pueblo Inga en Aponte Nariño (Colombia): Alli kausai o buen vivir. In B. Baptiste, D. Pacheco, M. C. de Cunha \& S. Diaz (Eds), Knowing our lands and resources: Indigenous and local knowledge of biodiversity and ecosystem services in the Americas. Paris: United Nations Educational, Scientific and Cultural Organization (UNESCO).

Cutter, S. (1996). Vulnerability to environmental hazards. Progress in Human Geography, 20(4), 529-539.

Cutter, S. L., Boruff, B. J., \& Shirley, W. L. (2006). Social vulnerability to environmental hazards. In S. L. Cutter (Ed.), Hazards, vulnerability and environmental justice (pp. 115-132). Abingdon: Earthscan.

Dover, R. V. (1995). Nucanchi gente pura: The ideology of recuperación in the Inga communities of Colombia's Sibundoy Valley (Doctoral dissertation). Indiana University: Bloomington.

Dynes, R. R. (2004). Expanding the horizons of disaster research. Natural Hazards Observer, 28(4), 1-2.

Equator Initiative (https://www.equatorinitiative.org/2017/05/30/wuasikamas-elmodelo-del-pueblo-inga-en-aponte/).

Fjord, L., \& Manderson, L. (2009). Anthropological perspectives on disasters and disability: An introduction. Human Organization, 68(1), 64-72.

Folke, C., Carpenter, S., Elmqvist, T., Gunderson, L., Holling, C. S., \& Walker, B. (2002). Resilience and sustainable development: building adaptive capacity in a world of transformations. AMBIO: A Journal of the Human Environment, 31(5), 437-440.

Gaillard, J.C. (2010). Vulnerability, capacity and resilience: Perspectives for climate and development policy. Journal of International Development, 22(2), 218-232. 
Gibson, T. D., Pelling, M., Ghosh, A., Matyas, D., Siddiqi, A., Solecki, W., ... Du Plessis, R. (2016). Pathways for transformation: Disaster risk management to enhance resilience to extreme events. Journal of Extreme Events, 3(1), 1-23.

Glantz, M. H. (1994). Creeping environmental problems. The World \& I, 218-225.

Gordon, O. E. (2014). The Andean cosmovision: A path for exploring profound aspects of ourselves, nature and the cosmos [Self-published book].

Harvey, P. (2007). Cash-based responses in emergencies. IDS Bulletin, 38(3), 79-81.

Hassler, U., \& Kohler, N. (2014). Resilience in the built environment. Building Research \& Information, 42(2), 119-129.

Hsu, E. L. (2017). Must disasters be rapidly occurring? The case for an expanded temporal typology of disasters. Time \& Society. Advance online publication. doi: https://doi.org/10.1177/0961463X17701956

Kelman, I., \& Stough, L. M. (2015). Disability and disaster: Explorations and exchanges. New York: Palgrave Macmillan.

Lindell, M. K. (1997). Part one: an assessment of existing research. International Journal of Mass Emergencies and Disasters, 15(3), 327-388.

Manyena, S. D. (2006). The concept of resilience revisited. Disasters, 30(4), 434-450.

Matin, N., Forrester, J., \& Ensor, J. (2018). What is equitable resilience? World Development, 109, 197-205.

Matthewman, S. (2015). Disasters, risks and revelation: Making sense of our times. Basingstoke: Palgrave Macmillan.

McEntire, D. A., \& Myers, A. (2004). Preparing communities for disasters: Issues and processes for government readiness. Disaster Prevention and Management, 13(2), 140-152.

Norris, F. H., Stevens, S. P., Pfefferbaum, B., Wyche, K. F., \& Pfefferbaum, R. L. (2008). Community resilience as a metaphor, theory, set of capacities, and strategy for disaster readiness. American Journal of Community Psychology, 41(1-2), 127150.

Oliver-Smith, A. (1977). Disaster rehabilitation and social change in Yungay, Peru. Human Organization, 36(1), 5-13.

Oliver-Smith, A. (1991). Successes and failures in post-disaster resettlement. Disasters, $15(1), 12-23$.

Oliver-Smith, A. (2009). Development \& dispossession: The crisis of forced displacement and resettlement. Santa Fe: School for Advanced Research Press. 
Oliver-Smith, A., \& de Sherbinin, A. (2014). Resettlement in the twenty-first century. Forced Migration Review, 45(1), 23-25.

Patel, S. S., Rogers, M.B., Amlôt, R., \& Rubin, G. J. (2017). What do we mean by 'community resilience'? A systematic literature review of how it is defined in the literature. PLoS Currents, 9.

Pelham, L., Clay, E., \& Braunholz, T. (2011). Natural disasters: What is the role for social safety nets? Washington DC: World Bank.

Pelling, M., O’Brien, K., \& Matyas, D. (2015). Adaptation and transformation. Climatic Change, 133(1), 113-127.

Quarantelli, E. L. (1998). Epilogue: Where we have been and where we might go: Putting the elephant together, blowing soap bubbles, and having singular insights. In E. L. Quarantelli (Ed.), What is a disaster? Perspectives on the question (pp. 239279). Abingdon: Routledge.

Régnier, P., Neri, B., Scuteri, S., \& Miniati, S. (2008). From emergency relief to livelihood recovery: Lessons learned from post-tsunami experiences in Indonesia and India. Disaster Prevention and Management: An International Journal, $17(3), 410-430$.

Retteberg, A. (2018). Peace-making as a struggle over the social contract: challenges and opportunities of the Peace Agreement in Colombia. SSRN. Online publication. doi: http://dx.doi.org/10.2139/ssrn.3205233

Sawada, Y., \& Takasaki, Y. (2017). Natural disaster, poverty, and development: An introduction. World Development, 94, 2-15.

Scoones, I. (2009). Livelihoods perspectives and rural development. The Journal of Peasant Studies, 36(1), 171-196.

Stallings, R. (2005). Disaster, crisis, collective stress, and mass deprivation. In R. W. Perry, \& E. L. Quarantelli (Eds.), What is a disaster? New answers to old questions (pp. 237-274). Bloomington: Xlibris.

Staupe-Delgado, R. (2019). Progress, traditions and future directions in research on disasters involving slow-onset hazards. Disaster Prevention and Management, Advance online publication. doi: https://doi.org/10.1108/DPM-11-2018-0358

Tierney, K., \& Oliver-Smith, A. (2012). Social dimensions of disaster recovery. International Journal of Mass Emergencies and Disasters, 30(2), 123-146. 
Tobin, G. A. (1999). Sustainability and community resilience: the holy grail of hazards planning? Global Environmental Change Part B: Environmental Hazards, 1(1), $13-25$.

Udmale, P. D., Ichikawa, Y., Manandhar, S., Ishidaira, H., Kiem, A. S., Shaowei, N., \& Panda, S. N. (2015). How did the 2012 drought affect rural livelihoods in vulnerable areas? Empirical evidence from India. International Journal of Disaster Risk Reduction, 13, 454-469.

UK Foreign and Commonwealth Office (2016). https://www.gov.uk/foreign-traveladvice/colombia

UN (2015). Sendai Framework for Disaster Risk Reduction 2015-2030. United Nations: New York.

UNISDR (2017). https://www.unisdr.org/we/inform/terminology

White, I., \& O'Hare, P. (2014). From rhetoric to reality: Which resilience, why resilience, and whose resilience in spatial planning? Environment and Planning C: Government and Policy, 32(5), 934-950.

Wikimedia Commons (2017a).

https://commons.wikimedia.org/w/index.php?title=File:Colombia__Nari\%C3\%B1o_-_El_Tab1\%C3\%B3n.svg\&oldid=240861581.

Wikimedia Commons (2017b).

https://commons.wikimedia.org/w/index.php?title=File:Colombia_Nari\%C3\%B1o.svg\&oldid=270108139.

Wisner, B., Blaikie, P., Cannon, T., \& Davis, I. (2004). At Risk: Natural hazards, people's vulnerability and disasters ( $2^{\text {nd }}$ edition). Abingdon: Routledge. 